\title{
Teoria e prática em economia solidária: problemática, desafios e vocação
}

\author{
Genauto Carvalho de França Filho*
}

\section{Introdução}

A temática da economia solidária vem conquistando visibilidade crescente nos últimos anos no Brasil. Seja através dos inúmeros trabalhos científicos que aparecem em várias universidades e em diferentes níveis, entre o ensino de graduação e pós-graduação, pesquisa e extensão, seja através da própria dinâmica no seio da sociedade civil e dos movimentos populares que conhecem a emergência crescente de novas iniciativas neste âmbito ou, ainda, através das inúmeras experiências de políticas públicas que vêm sendo empreendidas em diferentes cantos do país.

* Doutor em Sociologia pela Universidade de Paris VII; Professor da Escola de Administração da UFBA e do seu PPG (Npga/Ufba). Pesquisador do Cnpq. Organizador do livro Action publique et économie solidaire: une perspective internationale. Ramonville Saint-Agne: Érès, 2005 (Com Jean Louis Laville; Alzira Medeiros; Jean Philippe Magnen); Autor dos livros Sociétés en mutation et nouvelles formes de solidarité: le phénomène de l'économie solidaire en question - L'expérience des Régies de Quartier au carrefour des logiques diverses. Villeneuve d'Ascq: Presses Universitaires du Septentrion, 2003; Don et économie solidaire esquisse d'une théorie sócio-économique de l'économie solidaire. Paris: Mauss/Crida, 2000 (em parceria com Sylvain Dzimira). E-mail: genautofrancafilho@gmail.com

\begin{tabular}{|c|c|c|c|c|c|}
\hline Civitas & Porto Alegre & v. 7 & n. 1 & jan.-jun. 2007 & p. 155-174 \\
\hline
\end{tabular}


Esse apelo crescente pelo assunto tem conduzido a uma complexidade no seu tratamento, tornando a temática da economia solidária um objeto sujeito a múltiplas possibilidades de compreensão. Neste sentido, ao menos cinco caminhos para sua discussão parecem possíveis:

a) enquanto discussão conceitual: um modo fecundo de conhecer o tema é tratá-lo no nível conceitual, o que permite importantes reflexões sobre o sentido do agir econômico em sociedade. Nesse nível, o tratamento da economia solidária pode caminhar através de diferentes abordagens, entre enfoques economicistas e outros olhares mais antropológicos. $\mathrm{O}$ intuito aqui é fortalecer a compreensão teórica do assunto;

b) enquanto discussão contextual: neste nível a economia solidária é abordada a partir de sua manifestação concreta na realidade, como um problema de sociedade na contemporaneidade do capitalismo. Importa salientar como se situa o assunto em relação a outras questões cruciais da atualidade em diferentes contextos societários, como a crise do trabalho, a exclusão social e o combate à pobreza, a luta contra a desigualdade social e os modos de desenvolvimento local sustentável, etc. Busca-se aqui analisar a economia solidária como fenômeno e prática investigativa situadas em contextos societários específicos;

c) enquanto estudo de caso: neste nível, procura-se compreender a economia solidária enquanto fenômeno em si, a partir de suas práticas organizativas singulares. A idéia é entender sua dinâmica mais geral, partindo da análise de experiências concretas na forma de estudos de caso;

d) enquanto metodologia de intervenção: neste nível, a economia solidária é abordada como uma tecnologia social, ou seja, um instrumento ou ferramenta para geração de trabalho, renda e para a promoção de desenvolvimento sustentável em territórios caracterizados por alto grau de vulnerabilidade e exclusão social. A idéia é discutir a economia solidária no nível da própria operacionalidade das iniciativas, no sentido da formatação de técnicas ou tecnologias sociais para o fomento de transformações sociais. O caráter do conhecimento aqui assume grau elevado de prescrição, no intuito de sugerir meios de intervenção na realidade;

e) enquanto política pública: esta é a modalidade mais recente de tratamento do assunto, que vem ganhando status de política pública em função das inúmeras experiências já disseminadas em diferentes partes do país, no 
interior das estruturas de governo, e também em outros países. Neste nível, discute-se o caráter desse gênero novo de política pública, bem como seus efeitos e resultados alcançados.

Diante desse panorama, que aponta para a ampla abrangência no tratamento da temática, o presente trabalho tem intuito de transversalidade, no sentido de fixar um recorte no tema, de sua dimensão teórica à sua apreensão enquanto prática. O propósito do texto é didático, de apresentação do tema para o leitor neófito no assunto.

Nesta perspectiva, o texto explora inicialmente a dimensão conceitual da temática, em especial a fecundidade contida numa abordagem antropológica, em que são salientadas as possibilidades de uma re-significação do sentido do agir econômico em sociedade. Num momento seguinte, o tema da economia solidária é abordado como um campo de práticas em constituição no Brasil. Neste momento, discute-se diferentes modalidades de auto-organização sócio-econômica e política. Sublinha-se algumas problemáticas e desafios atravessando o campo, especialmente as interrogações sobre suas possibilidades concretas em termos de capacidades reais para gerar desenvolvimento territorial sustentável e constituir-se como alternativa efetiva à forma de desenvolvimento predominante, centrada na noção de economia de mercado. Salientase, ao final, a vocação fundamental de tais práticas, contida em seu conceito original, explorando-se a idéia, associada ao tema, de uma outra economia.

\section{Desconstruindo um conceito: a advertência necessária}

A compreensão da natureza singular das práticas de economia solidária supõe a desconstrução do difundido conceito de fato econômico, que o associa à noção de mercado ou troca mercantil.

Esta visão da economia como sinônimo de mercado encontra respaldo numa definição formalista, conforme os termos de Polanyi (1975), segundo a qual a economia é entendida como "toda forma de alocação de recursos raros para fins alternativos" (Robbins apud Caillé 2003, p. 220). Esta é a definição encontrada na maioria dos manuais de economia. De modo mais sintético, conforme sugere Caillé (2003, p. 220), esta definição formalista compreende por economia "todo comportamento visando economizar recursos raros pro- 
cedendo sistematicamente a um cálculo de custos e benefícios envolvidos numa decisão pensada como uma questão de escolha racional”.

Ao menos duas implicações problemáticas podem ser constatadas em decorrência dessa definição, indicando seu caráter reducionista. A primeira diz respeito ao pressuposto de escassez, caracterizando a realidade e o meio ambiente econômico a priori, através da ênfase sobre a noção de recursos raros. A segunda é relativa à visão de natureza humana, cujo comportamento é reduzido a uma questão de escolha racional, como se fosse próprio da ação e da conduta humana proceder sempre a partir de um "cálculo utilitário de conseqüências", segundo a expressão de Guerreiro Ramos (1989). Em suma, tal definição formalista de economia baseia-se na axiomática do interesse (Caillé 2002).

A definição substantiva, por outro lado, especialmente em seu sentido polanyiano, compreende a economia como "um processo institucionalizado de interação entre o homem e a natureza que permite um aprovisionamento regular de meios materiais para satisfação de necessidades" (Caillé, 2003, p. 221). Este sentido substantivo relaciona-se com a concepção aristotélica de economia e com a própria etimologia da palavra, remetendo à noção de ciência da boa gestão da casa (oikós) ou das condições materiais de existência.

Inspirados numa concepção muito próxima desta, os economistas clássicos ingleses (incluindo Marx) visualizam a economia política como o estudo científico da produção, da troca e da distribuição da riqueza material, ou, ainda, conforme resume Caillé (2003, p. 222) como a "a ciência dos sistemas econômicos, entendidos como sistemas de produção e de intercâmbio de meios para satisfazer necessidades materiais".

\section{Entre o conceito e a prática: a vocação da economia solidária como fundamento de uma outra economia}

\section{Combinando lógicas econômicas diversas}

A compreensão substantiva da economia pode, em resumo, associar a idéia de economia a toda forma de produção e de distribuição de riqueza - o que significa assumir o pressuposto básico de uma definição de economia como economia plural. Como as formas de "fazer economia", de produzir e distribuir riquezas, variaram historicamente nas diferentes culturas humanas, 
pode-se reconhecer diferentes economias, o que Polanyi (1983) denomina de diferentes princípios do comportamento econômico: o mercado autoregulado, a redistribuição, a reciprocidade e a domesticidade.

Estes diferentes princípios históricos do comportamento econômico podem resumir-se a três formas de economia (Laville, 1994), com o seu rearranjo na modernidade. Assim, a economia, entendida como toda forma de produzir e distribuir riqueza, admite:

a) uma economia mercantil: fundada no princípio do mercado autoregulado. Trata-se de um tipo de troca marcado pela impessoalidade e pela equivalência monetária, limitando a relação a um registro puramente utilitário. Neste tipo de troca/relação, o valor do bem (que se mede pelo seu preço) funda a lógica do sistema, ao contrário do primado do valor do laço ou da relação social, que se busca numa lógica reciprocitária;

b) uma economia não mercantil: fundada no princípio da redistribuição. É marcada pela verticalização da relação de troca e por seu caráter obrigatório, pois aparece a figura de uma instância superior (o Estado) que se apropria dos recursos a fim de distribuí-los;

c) uma economia não monetária: fundada no princípio da reciprocidade, ou seja, um tipo de relação de troca orientada principalmente pela lógica da dádiva, tal como descrita por Mauss (1978). A dádiva compreende três momentos: o dar, o receber e o retribuir. Neste tipo de sistema, os bens circulam de modo horizontal e o objetivo da circulação destes bens e/ou serviços vai muito além da satisfação utilitária das necessidades. Trata-se, sobretudo, de perenizar os laços sociais. A lógica da dádiva obedece, assim, a um tipo de determinação social específica pois, ao mesmo tempo livre e obrigada, a dádiva é essencialmente paradoxal (França Filho e Dzimira, 1999).

Em resumo, a noção de economia plural, que aqui adotamos como desdobramento da opção por uma definição substantiva de economia, corresponde à idéia de uma economia que admite uma pluralidade de formas de produzir e distribuir riquezas. Esse modo de conceber o funcionamento da economia real permite ampliar o olhar sobre o econômico para além da visão dominante, que reduz seu significado à idéia de economia de mercado, permitindo, ainda, perceber certas singularidades, próprias às práticas de economia solidária. 
A primeira dessas singularidades diz respeito à possibilidade de pensar as práticas de economia solidária como uma projeção, no nível micro ou mesosocial, do conceito macro-social de economia plural. A segunda, concerne à possibilidade de compreender a economia solidária como uma articulação inédita entre as três formas de economia citadas acima, inventando assim um outro modo de definir o ato econômico - ao invés de concebê-lo como uma "nova economia", que viria somar-se às formas dominantes de economia numa espécie de complemento que serviria de ajuste às disfunções do sistema econômico vigente,como se a economia solidária tivesse a função de ocupar-se dos pobres e excluídos do sistema econômico, constituindo uma espécie de setor à parte, com um papel funcionalmente bem definido em relação ao conjunto. A terceira singularidade remete à possibilidade de pensar as práticas de economia solidária como modos de gestão de diferentes lógicas em tensão nas dinâmicas organizativas. Neste sentido, enfatiza-se o desafio da busca do equilíbrio necessário à sustentabilidade de tais práticas, em meio à tensão dessas lógicas.

Contudo, para além dessa combinação de diferentes lógicas econômicas, traço que singulariza as práticas de economia solidária como fundamentos de uma outra economia, importa salientar, ainda, uma segunda vocação dessa economia, que aqui definimos como sendo a da construção conjunta da oferta e da demanda.

\section{Construindo conjuntamente a oferta e a demanda}

Tal vocação deve ser compreendida assumindo-se o pressuposto de que a economia solidária é construída por iniciativas de natureza associativa ou cooperativa que envolvem moradores que, num determinado contexto territorial, buscam a solução de problemas públicos concretos, relacionados à sua condição cotidiana de vida, através do fomento à criação de atividades sócioeconômicas. Neste sentido, a criação das atividades sócio-produtivas ou a oferta de serviços surgem em função de demandas reais, expressas pelos moradores em seu local. Tal economia estimula, no território, um circuito integrado de relações sócio-econômicas envolvendo produtores/prestadores de serviço e consumidores/usuários de serviços, numa lógica de rede.

Neste tipo de economia, perde sentido a consideração da oferta e da demanda como entidades abstratas, supostamente vocacionadas a harmonizarem-se graças à ação da mão invisível, num processo mais conhecido como 
auto-regulação do mercado. Do mesmo modo, a competição também deixa de ter importância nesta lógica. O objetivo da rede é a ruptura com a dicotomia habitual dos regimes de mercado, supostamente auto-regulados em relação à produção e o consumo (por seus efeitos danosos em temos sociais), e o estímulo à livre associação entre produtores e consumidores (ou prestadores de serviços e usuários), permitindo a criação do conceito de prossumidores.

Nesta economia de prossumidores, a regulação ocorre através de debates públicos no espaço associativo, num exercício de democracia local em que os próprios moradores planejam e decidem sobre a oferta de produtos e/ou serviços (ou seja, a criação das atividades sócio-econômicas), em função de suas próprias demandas, que são identificadas previamente.

Finalmente, a construção conjunta da oferta e da demanda como característica chave dessa outra economia supõe, ainda, no nível da ação, uma articulação fina entre as dimensões sócio-econômica e sócio-política. Isto porque a elaboração das atividades sócio-produtivas conjuga-se à uma forma de ação pública: trata-se de moradores num determinado território debatendo politicamente seus problemas comuns e decidindo seu destino. Tais iniciativas têm vocação para constituir-se, também, como formas inéditas de espaço público em seus respectivos territórios .

\section{Superando alguns reducionismos de visão}

Em resumo, o debate que empreendemos acima sobre a temática da economia solidária apresenta ainda o mérito de permitir ultrapassar quatro tipos de reducionismo amplamente praticados na análise teórica, que dificultam sobremaneira a compreensão deste assunto:

a) a redução da idéia de empresa à empresa mercantil: um desses reducionismos é a tendência a se conceber a empresa produtiva como sinônimo de empreendimento lucrativo com fins utilitários. Tal modo de pensar anula as possibilidades de implementar ações coletivas organizadas de natureza produtiva, e atividades econômicas sem fins de acumulação privada, para benefício de grupos e comunidades territoriais. Isto implica ampliar o conceito de empresa produtiva para além da norma capitalista, assim como redefinir os parâmetros de gestão comumente utilizados, na direção de um maior desenvolvimento e institucionalização de formas autogestionárias. 
b) a redução da idéia de economia à troca mercantil: um segundo reducionismo susceptível de superação nesse debate é aquele que associa economia exclusivamente à lógica utilitarista da economia de mercado ou da troca mercantil. Tal reducionismo impede a ampliação da compreensão do que seja o ato econômico e de seu sentido para a vida em sociedade, na direção de sua re-significação enquanto forma de produzir e distribuir riquezas. A superação de tal reducionismo permite enxergar as singularidades das formas diferentes de definir a economia, entre as quais aquela que coloca a solidariedade no centro da elaboração de atividades produtivas.

c) a redução da idéia de política ao Estado: um terceiro reducionismo consiste em separar a política da sociedade, ou seja, das práticas cotidianas dos cidadãos em seus respectivos territórios, como se o locus fundamental da política fosse exclusivamente as estruturas de Estado. A visão da economia solidária aqui trabalhada insiste na idéia da economia como um meio a serviço de outras finalidades: sociais, políticas, culturais, ambientais, etc, e não como um fim em si mesmo. Isto significa conceber as atividades econômicas constituídas através de iniciativas organizadas como formas de resolução de problemas públicos concretos num determinado território. As formas de economia solidária podem também ser percebidas como modos de ação pública, de fazer política no seio da própria sociedade, na medida em que tais iniciativas voltam-se para resolver problemas públicos vividos coletivamente num determinado contexto territorial. Trata-se, evidentemente, do fomento a uma política do cotidiano nos bairros e comunidades, que incita os cidadãos a agir.

d) a redução da ação humana à ação interessada: ao contrário das abordagens da ação social em termos de escolha racional, como se a característica da ação humana fosse proceder sempre e exclusivamente segundo um cálculo utilitário de conseqüências, numa visão que enfatiza a dimensão estratégica dos comportamentos individuais, a perspectiva da economia solidária abre-se para uma visão mais complexa do humano. Este é pensado antes de tudo como um ser simbólico, dotado de valores, e cujo comportamento não pode ser entendido em termos de previsibilidade mas, sobretudo, de incerteza. Se a necessidade, que por vezes impele os atores a condutas utilitárias, constitui um elemento não desprezível na análise dessa realidade, por outro lado, tal fator não pode ser considerado o motor exclusivo na explicação das condutas humanas, sobretudo em matéria de economia solidária. 


\section{Mergulhando na prática: contexto e problemática de uma economia popular e solidária no Brasil}

Sobre a realidade do fenômeno no Brasil, neste momento importa apresentar algumas considerações sobre a economia solidária como um campo de práticas em construção. Nossa hipótese é de que a dinâmica desse campo parece evoluir, de formas de auto-organização sócio-econômica, para formas de auto-organização sócio-política, o que nos leva a pensar tal campo como um tipo de movimento social de natureza singular, precisamente em função da característica dos atores que o compõem.

Consideraremos, a seguir, quatro categorias de atores ou instâncias organizativas que compõem o campo da economia solidária no Brasil. A primeira é constituída pelo que poderíamos definir como organizações de primeiro nível: os empreendimentos econômicos solidários (EES). Uma segunda categoria de atores, as organizações de segundo nível, reúne as entidades de apoio e fomento (EAF). A terceira categoria apresenta diferenças marcantes em relação às duas primeiras, por constituir-se quase que exclusivamente de formas de auto-organização política, ilustrada pelas redes e fóruns de economia solidária. Por fim, um quarto ator pode ser representado por uma espécie de nova institucionalidade pública de Estado. Dela são exemplos a rede de gestores de políticas públicas de economia solidária, a Secretaria Nacional para a Economia Solidária (Senaes), vinculada ao Ministério do Trabalho e Emprego, e, ainda, uma série de outras instâncias políticas do Estado (secretarias, diretorias ou departamentos), que estão tentando construir políticas públicas de economia solidária em governos municipais ou estaduais.

\section{As formas de auto-organização econômica: a centralidade dos EES}

As organizações de primeiro nível, ou empreendimentos econômicos solidários (EES), representam o núcleo fundamental de constituição do campo. Trata-se das formas, por excelência, de auto-organização sócio-econômica. Neste âmbito pode se alinhar diferentes experiências ou categorias, o que permite distinguir variadas práticas de economia solidária. Por exemplo, as finanças solidárias envolvem experiências de bancos populares, cooperativas de crédito e, mais recentemente, os bancos comunitários. Existem, também, 
as iniciativas que participam de uma categoria mais conhecida como comércio justo, além do segmento do chamado cooperativismo popular, expressão talvez majoritária no campo dos empreendimentos solidários. Deve-se incluir, ainda, iniciativas como os clubes de troca, que são formas muito específicas de práticas de economia solidária, constituindo uma categoria que poderíamos definir como uma "economia sem dinheiro". Em seguida, deve-se salientar as associações de moradores que constroem redes de práticas econômicas solidárias. Um caso muito conhecido no Brasil, e talvez emblemático, é o Banco Palmas, da associação de moradores do conjunto Palmeiras, em Fortaleza (CE). Ele consegue promover uma articulação entre diversas categorias de práticas de economia solidária, ao reunir num único empreendimento finanças solidárias, comércio justo e cooperativismo popular (ver França Filho, 2006a; França Filho e Laville, 2004, França Filho e Silva Junior, 2006).

Um traço marcante deste primeiro nível de auto-organização é o caráter heterogêneo do campo da economia solidária. Heterogeneidade que está refletida na coexistência de cooperativas populares ou cooperativas de trabalho e produção; organizações de trabalhadores que recuperam a massa falimentar de empresas e tentam criar um sistema de autogestão; bancos comunitários; clubes de troca; associações de serviços. etc. Neste sentido, o grau de heterogeneidade do campo deve ser considerado em relação a vários níveis de análise. O primeiro deles diz respeito ao âmbito de atuação das práticas solidárias, permitindo distinguir a economia solidária em sub-campos como o das finanças solidárias, o do comércio justo, o das formas de economia sem dinheiro, o do cooperativismo popular ou das empresas autogeridas. Um segundo nível de análise compreende as diferenças relativas ao grau de institucionalidade das próprias iniciativas, que permite distinguir as práticas mais consolidadas, envolvendo número significativo de pessoas e mobilizando recursos importantes, de outras iniciativas de menor porte, que beiram a informalidade e enfrentam grandes dificuldades quanto à sua sustentabilidade $\mathrm{e}$ quanto ao nível de renda gerado. Um terceiro elemento importante relativo à heterogeneidade dentro do campo da economia solidária diz respeito aos propósitos das iniciativas, elemento esse que distingue particularmente um empreendimento econômico solidário (EES) de uma entidade de apoio e fomento (EAF). 


\section{Descrevendo o papel das entidades de apoio e fomento (EAF): uma condição singular}

As entidades de apoio e fomento, como o próprio nome sugere, são estruturas organizativas dedicadas à assessoria dos empreendimentos econômicos solidários. Tais entidades podem ser organizações não governamentais com tradição no trabalho de organização popular ou de assessoria aos movimentos sociais. Podem, também, ser ONGs sem tal tradição, mas que detém expertise no trabalho e na organização de base social, ou num segmento específico das práticas de economia solidária. Podem ser, ainda, estruturas organizativas criadas no seio de universidades, ligadas a centros de pesquisa ou programas de extensão, ou, finalmente, podem ser estruturas de coordenação de redes.

Em geral, as entidades de apoio e fomento contam com uma base profissional altamente qualificada. Elas representam, de certo modo, a porção da sociedade civil mais organizada e institucionalizada atuando no campo da economia solidária. Seu papel é fortemente marcado pelo caráter de mediação social entre o mundo dos empreendimentos solidários (EES), com suas lógicas próprias, e as injunções relativas ao universo institucional no qual se inscrevem esses empreendimentos. $\mathrm{O}$ fomento e o apoio fornecidos pelas EAF costumam colocá-las como co-responsáveis, ao menos temporariamente, do processo de gestão dos empreendimentos, com vistas à consolidação do seu processo de sustentabilidade.

\section{Da economia popular à economia popular e solidária: desafios e problemática}

Reside precisamente neste aspecto o maior desafio para a consolidação desse campo de práticas. Como tornar sustentáveis iniciativas sócioprodutivas de base coletiva, democrática e solidária, num marco institucional dominado pelas normas da competição e da heterogestão? Como tornar perene o exercício prático de uma outra economia no contexto de um sistema em que predomina a economia de mercado? O que significa ser viável em matéria de economia solidária? Que estratégia deve guiar o caminho das práticas de economia solidária neste contexto: radicalizar a disputa com o capital, investindo na competitividade dos EES ou construir modos próprios de institucionalização de um outro agir econômico, com base em regulações territo- 
riais centradas no papel das associações locais entre produtores e consumidores, ou de redes de economia solidária?

Para uma compreensão mais fina desse desafio é preciso re-situar a economia solidária brasileira, especialmente a sua relação com a tradição mais antiga de economia popular, que parece exercer forte influência na constituição de grande parte das práticas neste campo. Os limites e a fronteira entre as duas noções devem esclarecer o sentido da expressão economia popular e solidária.

A economia popular diz respeito a um conjunto de atividades de produção, comercialização ou prestação de serviços efetuado coletivamente (e sob diferentes modalidades de trabalho associado) por grupos populares, principalmente no interior de bairros pobres e marginais das grandes cidades latinoamericanas. Tais grupos se estruturam de modo bastante informal e encontram nas relações de reciprocidade, tecidas no cotidiano de suas formas de vida e nos próprios laços comunitários, os fundamentos para tais práticas.

Esta economia popular permite a geração de trabalho para aqueles que estão às margens dos circuitos formais da economia, constituídos principalmente pelas esferas do Estado e do mercado. Entretanto, os níveis de renda que se obtém são bastante frágeis, garantindo, na maioria dos casos, apenas a sobrevivência dos grupos implicados em tais projetos. O desafio desta economia popular consiste, então, em ultrapassar o plano da "reprodução simples" das condições de vida, na direção da "reprodução ampliada". O que ocorre quando as atividades empreendidas impactam as próprias condições de vida das pessoas, isto é, em seu plano sócio-territorial maior, como a melhoria da infra-estrutura urbana, por exemplo. Este desafio é próprio do projeto de uma economia popular e solidária e deve ser aqui assinalado, em razão, precisamente, de certas qualidades ou características desta economia popular.

Tais qualidades compreendem um conjunto de aspectos que são absolutamente indissociáveis uns dos outros. O primeiro deles concerne à questão da participação ou engajamento das pessoas nos projetos solidários, o que remete ao grau de mobilização popular inerente a tais projetos. O segundo diz respeito ao modo de organização do trabalho nesses projetos, essencialmente baseado na solidariedade. Este registro da solidariedade, que é próprio do trabalho comunitário, vem acompanhado de uma série de outros princípios ou valores que servem de guia para a condução das práticas solidárias, como a cooperação e a gestão democrática dos projetos. 
Neste sentido de afirmação da solidariedade no interior da elaboração das práticas econômicas, a economia popular representa uma espécie de prolongamento das solidariedades ordinárias que são tecidas no interior dos grupos primários. Algumas dessas manifestações são bastante visíveis nos meios populares, conforme revela a prática mais conhecida sob o título de mutirão. O mutirão é uma forma de auto-organização popular, comunitária, coletiva e solidária, para a concretização de projetos ou para a resolução de problemas públicos concretos vividos pelas pessoas no seu cotidiano. Ele consiste em associar o conjunto dos moradores de uma comunidade na realização dos seus próprios projetos coletivos como, por exemplo a construção de equipamentos públicos ou de próprias casas. Trata-se, efetivamente, da implantação de atividades que são completamente indissociáveis da vida social do bairro. O final de um dia de trabalho em mutirão costuma sempre terminar numa grande festa coletiva popular, marcada, em geral, pela feijoada.

Percebe-se, nestas práticas, a força da dimensão não monetária. Porém, importa salientar que a economia popular não recobre todo o conjunto das atividades desenvolvidas nos meios populares. Sublinha-se aqui a diferença da economia popular em relação a outros modos de atividades econômicas oriundos dos setores populares como, por exemplo, a economia informal, que compreende iniciativas individuais sem relação com tradições locais nem com laços comunitários. A economia informal representa uma espécie de simulacro das práticas mercantis oficiais, pois trata-se de reproduzir tais práticas e a lógica que as acompanha, porém sem a adoção do registro legal - o que permitiria o acesso à direitos.

De uma certa maneira, a economia popular constitui um dos componentes dessa imensa economia dos setores populares, que compreende, além da economia informal e da própria economia popular, modalidades muito variadas de comércio subterrâneo ou ilícito, repousando sob o registro de solidariedades despóticas. Um dos exemplos mais emblemáticos é, sem dúvida, o da organização do tráfico de drogas em certas favelas na periferia de grandes cidades brasileiras. Esta economia do narcotráfico, baseada em formas de violência extremas, garante, em grande parte dos casos, níveis de renda bastante significativos para os envolvidos - o que explica em parte seu poder de sedução sobre certas categorias da população excluída, em especial sobre o público jovem. 
Assim, buscar as vias de superação de uma lógica de economia popular parece constituir, precisamente, o projeto de uma economia popular e solidária. O desafio desta economia consiste na aquisição de um certo nível de institucionalização, a fim de impactar de modo mais decisivo o meioambiente social e político onde se inscreve, ao mesmo tempo em que preserva suas qualidades de base, como a solidariedade, o trabalho comunitário, a cooperação e a gestão democrática dos projetos.

\section{As formas de auto-organização política}

A necessidade de superar o desafio da sustentabilidade tem conduzido as práticas de economia solidária na direção de um maior investimento no seu processo de estruturação política como campo. Neste sentido, mais do que iniciativas inovadoras e singulares em termos da abordagem econômica, o campo da economia popular e solidária no Brasil se impõe também, cada vez mais, como um movimento de atores em busca de reconhecimento institucional. Este movimento reivindica direitos, interroga políticas públicas existentes e propõe outras. O objetivo é propor uma mudança institucional na direção do reconhecimento de um outro modo de instituir a prática econômica. A expressão concreta desse movimento são as redes e os fóruns, seus principais modos de auto-organização política. Porém, sendo os fóruns também formas de redes, trata-se, então, de dois modos de expressão de difícil distinção e que apresentam, ainda, a tendência a se articularem, o que remete a um debate político sobre o lugar de cada modo de auto-organização, sobre as relações que mantêm entre si e com os poderes públicos.

Em primeiro lugar, as redes são a forma de auto-organização mais evidente e mais antiga. Ela consiste num associacionismo mais amplo, compreendendo um certo número de experiências concretas de organizações de fomento e apoio que compartilham valores e regras comuns. As redes se estendem em diferentes escalas entre o local, o regional, o nacional e o internacional. Essa é, por excelência, a forma de organização, dos movimentos associativos atuais. Suas características comportam inovações importantes em relação à tradição de organização dos movimentos sociais e políticos, com implicações consideráveis no plano da distribuição de poder nestas instituições, o que representa uma mudança grande em relação às estruturas anteriores, que 
eram muito hierárquicas. Neste sentido, parece instituir-se novas modalidades de estabelecimento do ato político.

As redes guardam um traço político forte, ao constituírem-se exclusivamente a partir das experiências oriundas da sociedade, com independência em relação aos poderes públicos. Entretanto, levando-se em consideração o lugar cada vez mais importante assumido pelo tema da economia solidária no interior de certas estruturas de governo que decidem pela formulação de políticas públicas para este setor, tende a se estabelecer uma relação de interdependência com os poderes públicos, em termos da instauração de novos espaços de intercâmbio e de troca de experiências. A recente criação da rede nacional de gestores de políticas públicas de economia solidária vem testemunhar a complexidade deste campo.

Os fóruns, por sua vez, também são espaços de reunião de atores, mas numa dimensão mais ampla, pois supõem, também, a participação de representantes de instituições públicas. Ao mesmo tempo em que reivindicam sua autonomia enquanto espaço de atores da sociedade civil, os fóruns se abrem para uma relação de interdependência em relação aos poderes públicos.

Da mesma forma que as redes, os fóruns representam espaços de aglutinação de atores para discussão dos seus problemas comuns. As tentativas de fortalecer o seu desenvolvimento têm como objetivo tornar mais legítimo o campo da economia solidária. Por isto a relação com os poderes públicos torna-se importante. Os fóruns se impõem como interlocutores privilegiados do movimento de economia solidária junto ao Estado, especialmente junto à Secretaria Nacional para Economia Solidária (Senaes). Além de ações pontuais, relativas à organização do movimento de atores com origens bastante diversificadas, a tarefa principal dos fóruns parece ser a de intervir na definição de políticas públicas, através do encaminhamento de proposições. Neste nível, os fóruns desempenham um papel decisivo na mudança institucional necessária para a consolidação deste campo: a instituição de um quadro de regulação jurídico-político, de um marco legal que permita legitimar e fortalecer a especificidade das práticas de economia solidária.

Em resumo, os fóruns, assim como as redes, apresentam um caráter ao mesmo tempo militante e de assistência técnica. Mas os fóruns são também espaços de reunião dos atores, num sentido mais abrangente do que as redes, pela presença e participação de representantes dos poderes públicos gover- 
namentais. Ao mesmo tempo em que reivindicam sua autonomia enquanto espaço de atores da sociedade civil, os fóruns se constituem como espaços de intermediação em relação ao Estado. Tais espaços agrupam as diversas partes que compõem o movimento de economia solidária - pesquisadores, entidades de apoio e fomento, gestores públicos e os próprios atores - cujo engajamento ocorre fundamentalmente de maneira voluntária.

Portanto, no nível das redes e dos fóruns, o campo da economia solidária, um campo em construção, conseguiu progressos significativos na institucionalização necessária à sua prática, visto que a mudança da realidade e a promoção do desenvolvimento supõem o salto da sobrevivência para a sustentabilidade dessas iniciativas. Faz-se necessário superar a precariedade e conseguir impactar o contexto mais geral da realidade onde se instaura a economia solidária, para além dos benefícios concedidos àqueles mais diretamente envolvidos nas iniciativas ou empreendimentos solidários. Para isso, o fortalecimento de um marco institucional como complemento à espontaneidade das iniciativas assume grande importância.

Neste sentido, os fóruns apresentam maior grau de institucionalização no campo, pois já conseguem promover um processo de interlocução política. Mas, ao mesmo tempo, eles têm um papel difícil porque tentam reunir algo que, por natureza, não é unificado, já que as práticas solidárias são heterogêneas. A economia solidária reúne e tenta unificar atores com características e origens distintas e práticas também diferentes. Trata-se de um processo muito difícil, doloroso às vezes. A história ainda muito recente dos fóruns estaduais revela níveis de conflito e de desgastes importantes, porém tal dinâmica é parte constitutiva do processo de organização social e política do movimento, acabando por funcionar como um processo de aprendizado da democracia para os diversos atores.

Em suma, as formas de auto-organização política da economia solidária sugerem que existem, nesse campo, atores em movimento. É nesse nível que podemos pensar a economia solidária como uma forma específica de movimento social (França Filho, 2006c), um movimento social, ao que parece, de tipo radicalmente novo, pois operando por dentro da economia. 


\section{Considerações finais: a participação crescente dos poderes públicos}

Se o campo da economia solidária no Brasil tem evoluído de formas de auto-organização sócio-econômica inovadoras para modos de autoorganização políticos também inéditos no âmbito da sociedade civil, hoje tal dinâmica parece complexificar-se e enriquecer-se ainda mais, com a participação cada vez maior dos próprios poderes públicos. A expressão mais acabada dessa relação tem sido o aparecimento e a multiplicação das políticas públicas dedicadas ao assunto, sobretudo no nível das prefeituras municipais.

O crescimento progressivo de tais políticas no Brasil levou ao surgimento de um novo ator neste campo, com um importante papel a desempenhar: trata-se da rede brasileira de gestores de políticas públicas de economia solidária. De pouco mais de duas dezenas de representações, quando do seu surgimento em 2004, esta rede reúne, hoje, mais de uma centena de representações, refletindo o crescimento do número de experiências de políticas públicas de economia solidária em curso no país.

Este crescimento súbito não acontece sem problemas: o tema da economia solidária muitas vezes é captado, por certas estruturas de governo, como mais um modismo, apoiando-se, assim, em bases muito frágeis de tratamento da questão da geração de trabalho e renda (França Filho, 2006b). Porém, um dos papéis mais importantes da rede brasileira de gestores, em parceria com a Senaes e outros atores, como a Fundação Josué de Castro, é exatamente o nivelamento necessário para a compreensão do tema, que passa por um intenso programa de formação dos gestores públicos em seus diferentes níveis.

De todo modo, há que se ressaltar, com base em algumas experiências em curso, a importância de tais políticas para redefinir as relações entre sociedade civil e poder político, no sentido de sua maior democratização, ampliando efetivamente nossa forma de conceber e realizar a ação pública. Isto porque um aspecto basilar na concepção e implementação de tais políticas diz respeito à necessidade de interações recíprocas entre o poder público e outros atores, o que aparece de modo mais evidente nas experiências mais exitosas .

Tais interações, parcerias ou articulações tendem a ocorrer em dois níveis. $\mathrm{O}$ primeiro deles concerne às articulações entre os atores da sociedade civil que compõem o campo da economia solidária e seus espaços públicos 
constituídos, como os fóruns, que se tornam interlocutores diretos na concepção, implementação e avaliação da política. O segundo aspecto diz respeito à vocação que tais políticas possuem de suscitar interações dentro da própria estrutura de governo, incitando ao diálogo e à ação conjunta as secretarias de Estado. Isto se deve à natureza dos problemas mobilizados pela economia solidária, que implicam na transversalidade de tratamento. Conforme sublinha Schwengber (2006, p. 294), “essa política demanda ações transversais que articulem instrumentos de várias áreas (educação, saúde, trabalho, habitação, desenvolvimento econômico, saúde e tecnologia, crédito e financiamento, entre outras) para criar um contexto efetivamente propulsor da emancipação e sustentabilidade". Evidentemente, tais características muitas vezes existem apenas na intenção, sem efetiva realização, pelas dificuldades próprias à natureza da relação política, profundamente conflituosa, seja no interior da máquina de governo, seja entre o poder público e os atores da sociedade civil. Contudo, trata-se aqui de um horizonte que começa a desenhar-se como prática e aprendizado para muitos atores, em experiências que já caminham nesta direção.

Saliente-se, ainda, que o caráter de transversalidade no modo de intervenção de tais políticas, acima mencionado, decorre de sua segunda vocação, a propensão a se constituir como políticas de desenvolvimento. Ao se dirigirem a um público historicamente excluído, tais políticas respondem a demandas efetivas do campo mais estruturado da economia solidária, mas também induzem processos de auto-organização coletiva e solidária. Neste sentido, a política de geração de trabalho e renda, numa perspectiva sustentávelsolidária (França Filho, 2006b), associa-se diretamente a uma concepção de desenvolvimento com enfoque territorial e a visão e regulação da economia consubstanciado nessa idéia.

Em resumo, as práticas de economia popular e solidária no Brasil ganharam em complexidade nos últimos anos, afirmando-se como um campo de atores que inventam alternativas econômicas e políticas inovadoras para a resolução dos problemas cotidianos enfrentados em seus respectivos territórios, decorrentes dos processos de exclusão social. De iniciativas originais no plano sócio-econômico, em que também se afirma uma dimensão política forte - seja através da democratização das relações de produção em direção a processos autogestionários, seja pela afirmação de um novo espaço público de proximidade, naquelas experiências em que se vivencia um outro modo de 
instituir a economia nos territórios, através de processos de construção conjunta da oferta e da demanda - surgem formas de auto-organização política, indicando a constituição de espaços públicos de um segundo nível (França Filho, 2006a) em relação aos de proximidade. Mais recentemente, constata-se a multiplicação crescente de políticas públicas de economia solidária, fato novo na dinâmica deste campo, uma vez que tais políticas intervêm no seio de espaços públicos em diferentes níveis, redefinindo as relações entre sociedade civil e poder político, numa abordagem ampliada da ação pública.

\section{Referências}

CAILLÉ, A. Sur les concepts d'économie en général et d'économie solidaire en particulière. La Revue du Mauss semestrielle, n. 21 (Alter-économie: quelle autre mondialisation?), Paris: La Découverte, 2003.

CAILLÉ , A., Antropologia do dom. Petrópolis: Vozes, 2002.

FRANÇA FILHO, G., A economia popular e solidária no Brasil, In: FRANÇA FILHO, G.; LAVILLE, J.; MEDEIROS, A.; MAGNEN, J. P. (Orgs.). Ação pública e economia solidária: uma perspectiva internacional, Porto Alegre/Salvador: EdufrgsEdufba, 2006a.

FRANÇA FILHO, G. Políticas públicas de economia solidária no Brasil: características, desafios e vocação. In FRANÇA FILHO, G.; LAVILLE, J.; MEDEIROS, A.; MAGNEN, J. P. (Orgs.). Ação pública e economia solidária: uma perspectiva internacional, Porto Alegre/Salvador: Edufrgs-Edufba, 2006b.

FRANÇA FILHO, G; SILVA Jr. Uma dinâmica associativa emblemática no nordeste brasileiro, In: FRANÇA FILHO, G.; LAVILLE, J.; MEDEIROS, A.; MAGNEN, J. P. (Orgs.). Ação pública e economia solidária: uma perspectiva internacional, Porto Alegre/Salvador: Edufrgs-Edufba, 2006.

FRANÇA FILHO, G. Economia solidária e movimentos sociais. In: MEDEIROS, A.; SCHIOCHET, V.; SCHWENGBER, A. Políticas públicas de economia solidária: por um outro desenvolvimento. Recife: Edufpe, 2006c.

FRANÇA FILHO, G.; LAVILLE, J.; MEDEIROS, A.; MAGNEN, J. P. (Orgs.). Action publique et économie solidaire: une perspective internationale. Toulouse: Eres, 2005.

FRANÇA FILHO, G.; LAVILLE, J. L. Economia solidária: uma abordagem internacional. Porto Alegre: Edufrgs, 2004.

FRANÇA FILHO, G. A problemática da economia solidária: um novo modo de gestão pública? Cadernos Ebape, FGV-RJ, v. 2, n. 1, mar. 2004. 
FRANÇA FILHO, G. En croisant le regard: l'économie solidaire en France et au Brèsil. La revue du MAUSS, semestrielle, n. 21 (Alter-économie: quelle autre mondialisation?), Paris: La Découverte, 2003a.

FRANÇA FILHO, G. A temática da economia solidária e suas contribuições originais para o campo dos estudos organizacionais. Revista de Administração Pública (RAP), Rio de Janeiro, n. 37(1), jan.- fev. 2003b.

FRANÇA FILHO, G. Terceiro setor, economia social, economia solidária e economia popular: traçando fronteiras conceituais. Bahia análise e dados. Salvador: SEI/Governo da Bahia, 2002b, v. 12, n. 1, jun. 2002.

FRANÇA FILHO, G.; DZIMIRA, S. Economia solidária e dádiva. Revista Organizações \& Sociedade, Salvador, Escola de Administração/Ufba, v. 6, n. 14, jan.-abr. 1999.

GUERREIRO RAMOS, A. A nova ciência das organizações: uma reconceituação da riqueza das nações. São Paulo: FGV, 1989.

LAVILLE, J. L. Définitions et institutions de l'économie: pour un dialogue maussien. La Revue du MAUSS semestrielle, n. 27 (De l'antiutilitarisme - anniversaire, bilan et controverses), Paris: La Découverte, 2006.

LAVILLE, J. L.(Org.). L'économie solidaire: une perspective internationale. Paris: Desclée de Brouwer, 1994.

MAUSS, M.. Essai sur le don: forme et raison de l'échange dans les sociétés archaïque, In: MAUSS, M. Sociologie et anthropologie. Paris: PUF, 1978.

POLANYI, K. Les systèmes économiques: dans l'histoire et dans l'économie. Paris: Librairie Larousse, 1975.

POLANYI, K., La grande transformation: aux origines politiques e économiques de notre temps. Paris: Gallimard, 1983.

SCHWENGBER, A. Diretrizes para uma política pública de economia solidária no Brasil. In: FRANÇA FILHO, G.; LAVILLE, J.; MEDEIROS, A.; MAGNEN, J. P. (Org.). Ação pública e economia solidária: uma perspectiva internacional. Porto Alegre/Salvador: Edufrgs-Edufba, 2006. 